\title{
UCRL-CONF-155806
}

LAWRENCE LIVERMORE NATIONAL LABORATORY

\section{The National Ignition Facility}

G. H. Miller

December 19, 2003

SPIE - The International Society for Optical Engineering, Lasers and Applications in Science and Engineering, San Jose, California, January 25-29, 2003 
This document was prepared as an account of work sponsored by an agency of the United States Government. Neither the United States Government nor the University of California nor any of their employees, makes any warranty, express or implied, or assumes any legal liability or responsibility for the accuracy, completeness, or usefulness of any information, apparatus, product, or process disclosed, or represents that its use would not infringe privately owned rights. Reference herein to any specific commercial product, process, or service by trade name, trademark, manufacturer, or otherwise, does not necessarily constitute or imply its endorsement, recommendation, or favoring by the United States Government or the University of California. The views and opinions of authors expressed herein do not necessarily state or reflect those of the United States Government or the University of California, and shall not be used for advertising or product endorsement purposes. 


\title{
The National Ignition Facility
}

\author{
George H. Miller \\ Lawrence Livermore National Laboratory, P.O. Box 808 L-466, Livermore, CA 94551
}

\begin{abstract}
The National Ignition Facility (NIF) at Lawrence Livermore National Laboratory is a stadium-sized facility containing a 192-beam, 1.8-Megajoule, 500-Terawatt, ultraviolet laser system together with a 10-meter diameter target chamber and room for 100 diagnostics. NIF is the world's largest and most energetic laser experimental system, providing a scientific center to study inertial confinement fusion and matter at extreme energy densities and pressures. NIF's energetic laser beams will compress fusion targets to conditions required for thermonuclear burn, liberating more energy than required to initiate the fusion reactions. Other NIF experiments will study physical processes at temperatures approaching $10^{8} \mathrm{~K}$ and $10^{11}$ bar; conditions that exist naturally only in the interior of stars and planets. NIF has completed the first phases of its laser commissioning program. The first four beams of NIF have generated 106 kilojoules in 23-ns pulses of infrared light and over $16 \mathrm{~kJ}$ in $3.5 \mathrm{~ns}$ pulses at the third harmonic $(351 \mathrm{~nm})$. NIF's target experimental systems are being commissioned and experiments have begun. This paper discusses NIF's current and future experimental capability, plans for diagnostics, cryogenic target systems, specialized optics for experiments, and potential enhancements to NIF such as multi-color laser operation and high-energy short pulse operation.
\end{abstract}

Keywords: High Energy Density Physics, Inertial Confinement Fusion, Laboratory Astrophysics, Solid State Lasers

\section{INTRODUCTION}

The National Ignition Facility (NIF) under construction at the Lawrence Livermore National Laboratory (LLNL) for the U.S. Department of Energy and National Nuclear Security Administration (NNSA) will be a scientific center for the study of inertial confinement fusion and the physics of extreme energy densities and pressures. Construction of the building that houses the laser system was completed in September 2001 and the installation of all 192 ultra-clean and precision aligned beam path enclosures was completed in September 2003. In late 2002 NIF began activating its first four laser beam lines. By July 2003 NIF had delivered world-record single laser energy performance in primary (1.06 micron), second, and third harmonic wavelengths. When completed in 2008, NIF will provide up to 192 energetic laser beams to compress deuteriumtritium fusion targets to conditions where they will ignite and burn, liberating more energy than is required from the laser to initiate the fusion reactions. NIF experiments will allow the study of physical processes at temperatures approaching 100 million $\mathrm{K}$ and 100 billion times atmospheric pressure. These conditions exist naturally only in the interior of stars and in nuclear weapons explosions. ${ }^{1-6}$

Detailed descriptions of NIF's laser architecture and the performance of the laser system is presented in accompanying presentations at this Conference. ${ }^{7-24}$ In addition to the laser system, the first diagnostic systems to be used for both laser performance measurements and physics experiments have been installed and commissioned. These include static $x$-ray imaging, gated and streaked $\mathrm{x}$-ray detectors mounted on the NIF target chamber and a full aperture back-scatter diagnostic that images scattered light through the final optical beampath of the first quad of four beams. With this initial suite of diagnostics NIF experimenters have completed the first studies related to ignition hohlraum energetics and hydrodynamics. ${ }^{25}$

\section{HIGH ENERGY DENSITY PHYSICS ON NIF}

The National Ignition Facility extends the high-energy-density (HED) experimental regimes of current and planned highenergy laser and pulsed power facilities by a significant amount. Figure 1 shows one measure of NIF's physics reach for temperature and density of materials. In this figure we show how NIF can reach conditions of matter that exist in the sun and larger stars, giant planes such as Jupiter, and brown dwarfs, dead or dying stars, which are 


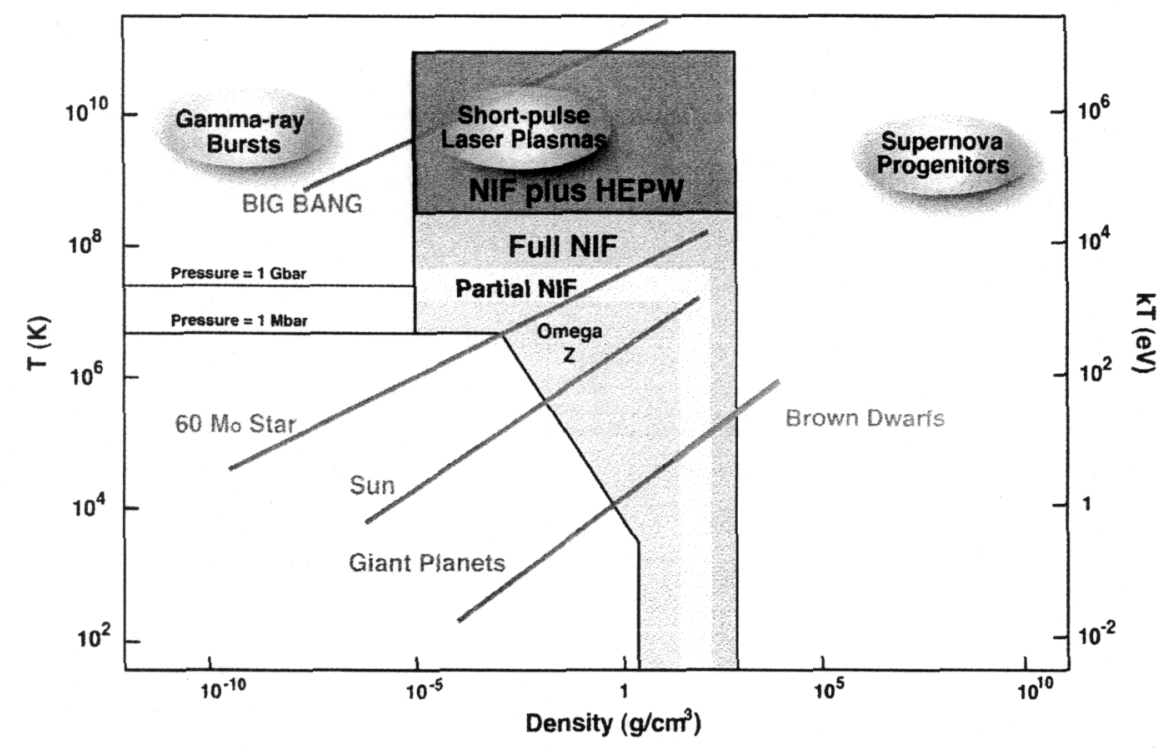

Fig. 1. High energy density is a prevailing condition in astrophysics. This figure shows how NIF compares with currently available facilities - the $30 \mathrm{~kJ}$ Omega Laser at the University of Rochester and the Z machine at Sandia National Laboratories. NIF with shortpulse laser capability can reach conditions approaching those near the time of the Big Bang. ${ }^{27}$

thought to make up a significant amount of the matter in our universe. Some of NIF's beams can also be equipped withshort pulse lasers and the combined high energy and high power laser beams delivered to targets. Under these conditions NIF can reach extreme states of matter more typically associated with nuclear and high energy physics accelerator experiments. In this way NIF can explore the physics of matter at temperatures approaching those that existed in the very early universe.

Another way of expressing NIF's capabilities is shown in Figure 2 that shows the pressure versus pulse length achievable in a number of facilities. NIF can drive materials to tens of gigabars for pulse lengths of tens of nanoseconds. NIF is capable of providing a range pulse lengths that under certain configurations can be hundreds of nanoseconds. The ability to deliver extended high-energy drive allows experimental measurements of equation of state (EOS), materials at high pressures, hydrodynamics, and radiation transport that have not been possible in prior HED facilities.

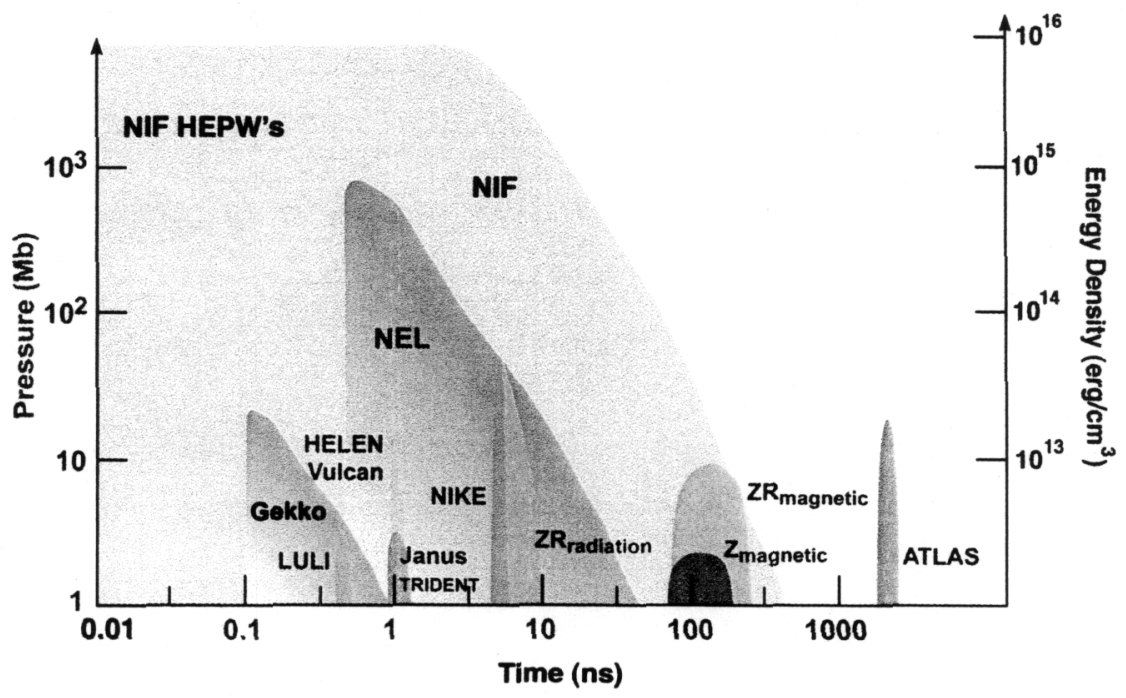

Fig. 2. Pressure-pulse length regimes accessible at different HED facilities currently operating or planned in the world. NEL refers to NIF Early Light (4 beams). Laser facilities include Gekko (Japan), LULI (France), Helen and Vulcan (UK), Janus, Trident, NIKE (US). $\mathrm{Z}$ and Atlas are pulsed power facilities at Sandia and Los Alamos National Laboratories. 

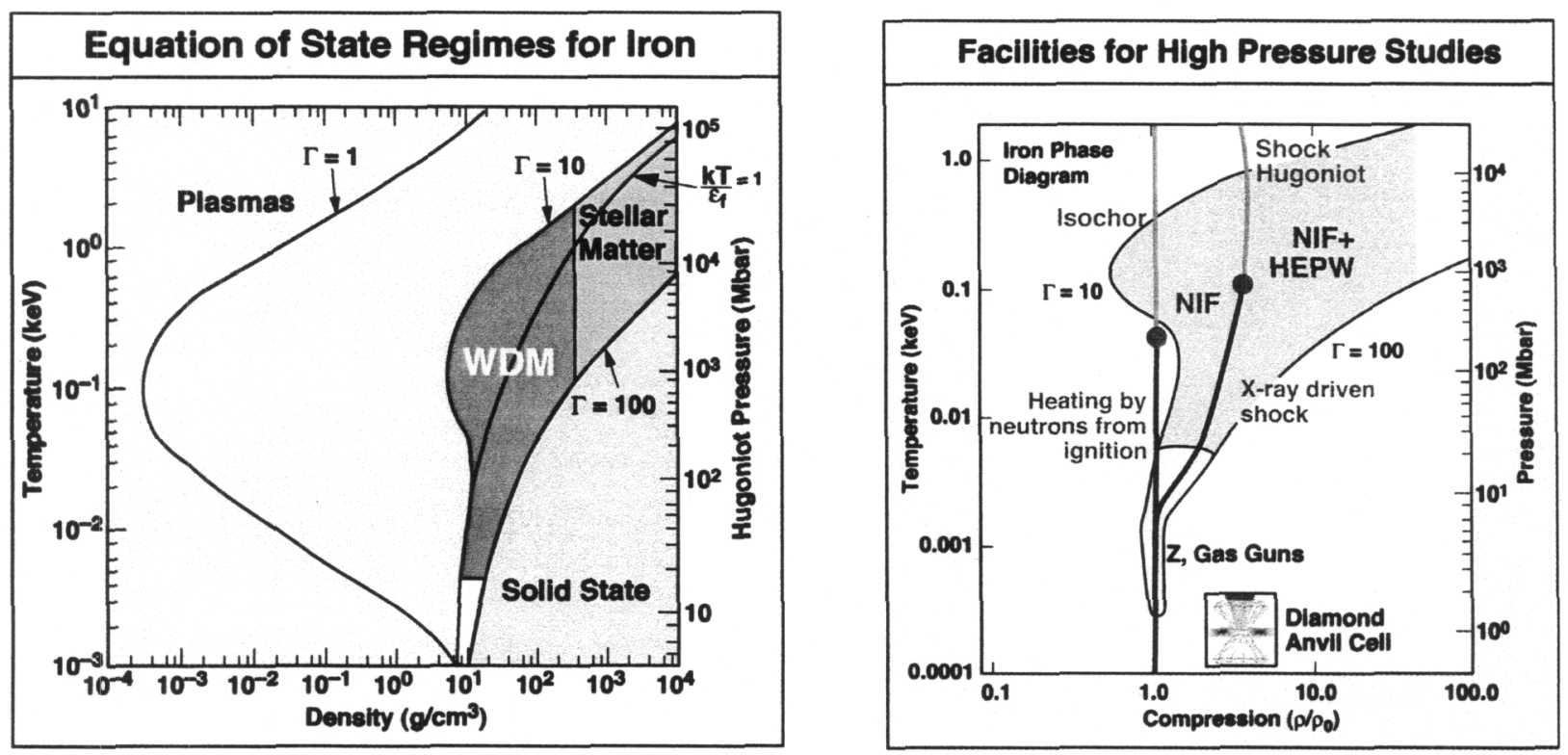

Fig. 2a, left, shows the phase space for iron with the warm dense matter (WDM) phase highlighted. The lines labeled with $\Gamma$ referring to the strength of coupling between ions, with higher $\Gamma$ being strongly coupled. Also shown is the approximate location of electron degeneracy $\mathrm{kT} / \varepsilon_{\mathrm{f}}=1$. Fig. $3 \mathrm{~b}$, right, details NIF's ability to reach high pressures using long pulse NIF, NIF plus HEPW and NIF ignition neutrons to isochorically heat materials to off-Hugoniot conditions. Other facilities such as z-pinch, gas gun, and diamond anvil cells are shown for comparison.

NIF opens up new fields of study, for example in the area of warm dense matter (WDM) - approximately solid density matter at temperatures in the few $\mathrm{eV}$ to tens of $\mathrm{eV}$ range ${ }^{26,27}$ Figure $3 \mathrm{a}$ shows an example the EOS regimes for iron. In WDM ions are strongly coupled (represented in Figs. $3 \mathrm{a}$ and $3 \mathrm{~b}$ by the parameter $\left.\Gamma=(\mathrm{Ze})^{2} / \mathrm{a}\right) / \mathrm{kT}$ ), electrons are partially degenerate, i.e., the thermal energy kT approaches the Fermi energy $\varepsilon_{f}$, and the material is partially ionized due to continuum lowering and pressure ionization. Currently there is no theory that adequately describes WDM.

Figure $3 \mathrm{~b}$ shows how NIF can be used to provide high accuracy high-pressure measurements of WDM. NIF's high-energy laser beams can be tailored for driving relatively large uniform volumes. NIF beams can also be used to provide high $\mathrm{x}$-ray fluences for high signal-to-noise radiography of dense matter. Recent experiments using laser-generated isentropic plasma pistons (ICE drive) to steadily load materials to high pressure as shown in Figure 4 have been demonstrated on the Omega Laser at the University of Rochester Laboratory for Laser Energetics and are being planned on NIF. ${ }^{28-30}$ As more NIF beams become available it is expected that extremely high pressures can be generated using long-pulse generated shocks and ICE techniques along with unprecedented measurement accuracy associated with smoothing capability and new high precision target fabrication techniques. High-energy short-pulses can provide extremely high brightness and high-energy $\mathrm{x}$ ray backlighter sources for radiographing WDM to fully resolve hydrodynamic features and materials states. ${ }^{31,32}$

Even with the first four beams of NIF experiments can reach tens to one hundred megabars in materials. Initial EOS experiments with the first four NIF beams are planned in the coming year that have a goal of exceeding 25 Mbar in aluminum $^{33}$ in a steady and uniform pressure wave. Isochoric heating with ignition neutrons or high energy petawatt lasergenerated ion beams when they become available in the coming decade provides an additional capability for heating materials off the Hugoniot.

Dynamic strength of materials at extreme pressure and strain rate is another area of great experimental and theoretical uncertainty. Large increases in materials strength are predicted as pressure and strain rate increase, however there is no controlled data currently available to support this prediction. Recent measurements on Omega have demonstrated RayleighTaylor (RT) strength diagnostic techniques, which utilize laser driven plasma pistons to initiate and evolve RT instabilities in an engineered sample over time with radiographic measurements of the induced deformation giving information on dynamic material strength. Figure 5 shows how experiments to deduce materials strength using RT-growth techniques are fielded on laser systems. ${ }^{34}$ 

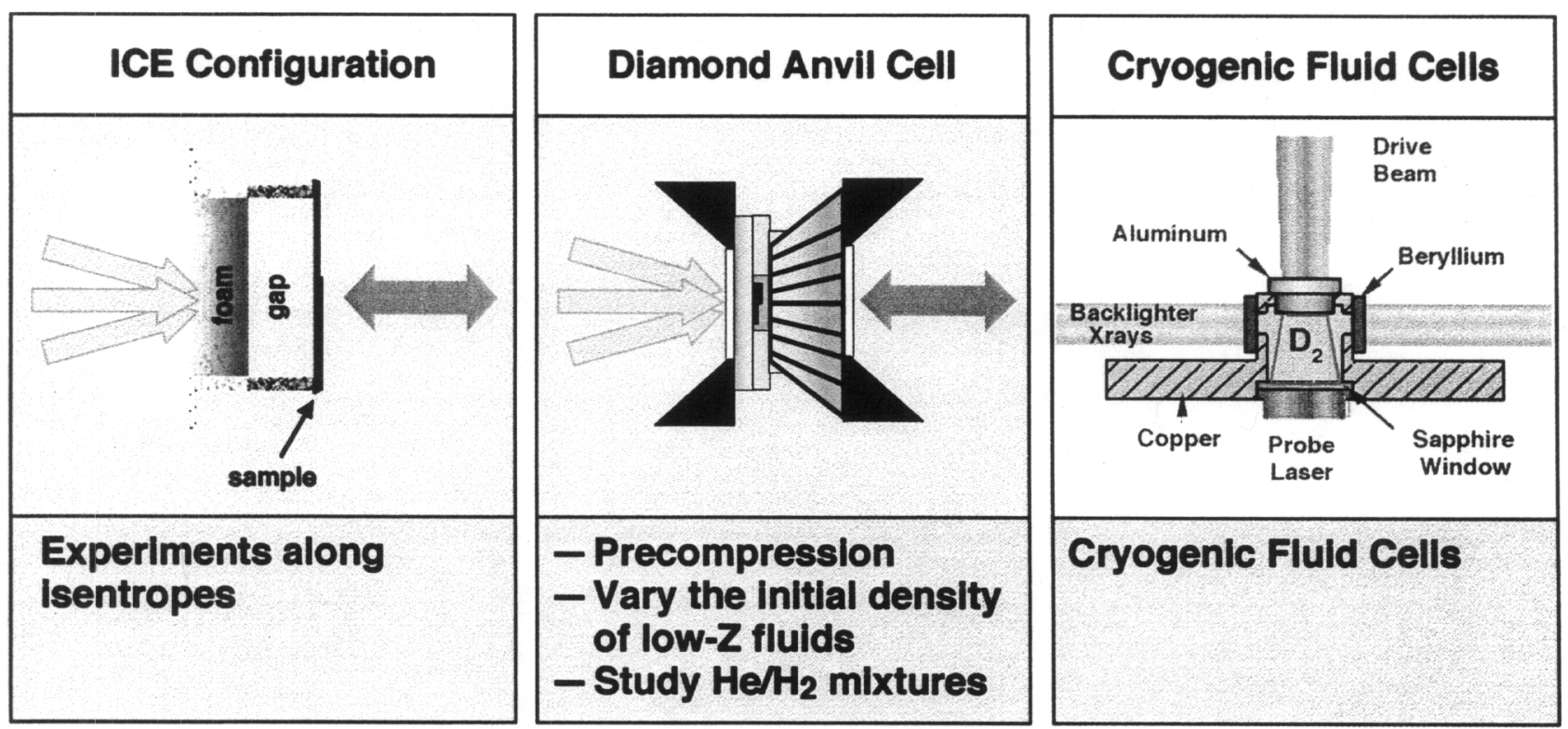

Fig. 4. Advanced target configurations demonstrated on lasers for measuring materials properties. The ICE target on the left uses lasers to create a plasma piston that traverses a gap and gently loads the sample to high pressure. Laser interferometry is used to analyze the sample's strength by measuring its velocity. Other targets are shown in the middle and right where samples preloaded in diamond anvil cells or cryogenically-cooled can be fielded to study other states of matter not normally accessible.

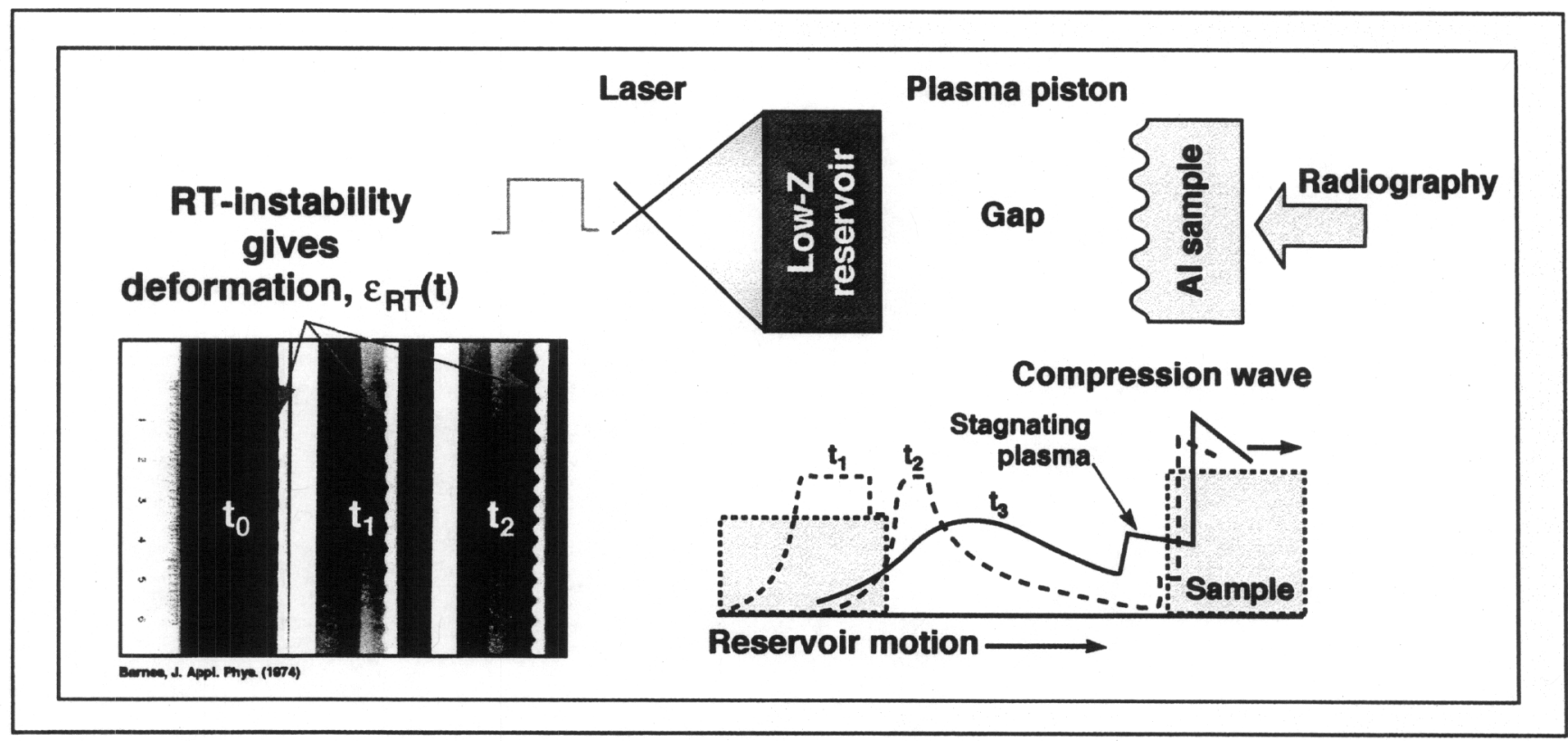

Fig. 5. Materials strength can be deduced using lasers to drive engineered samples to induce Rayleigh-Taylor (RT) instabilities that grow in time. In this figure a rippled aluminum sample is loaded by a low atomic number plasma traversing a gap. The photographs at the lower left show an experimental example of evolving RT instabilities as a function of time. By measuring the growth of these instabilities material strength can be derived. 


\section{IGNITION ON NIF}

One of the key missions of NIF is to generate and study thermonuclear ignition and energy gain using the 192 lasers of NIF to compress and heat small capsules containing a mixture of the heavy hydrogen isotopes of deuterium and tritium. Figure 6 shows how inertial confinement fusion (ICF) is carried out using lasers. Carefully prepared ignition capsules containing the fusion fuel in a thin, very smooth frozen layer surrounding a pressurized DT gas volume are contained in precisely formed plastic or copper-doped beryllium shells. The capsule is suspended in a hollow gold cylinder with laser entrance windows on each end called a hohlraum. Carefully focused and temporally-shaped laser beams are directed into the hohlraum through the ends and deliver their energy to the inside walls, generating intense $\mathrm{x}$-rays that uniformly illuminate the capsule. The $\mathrm{X}$ rays ablate the outer surface of the capsule away very rapidly and the reaction force from the ablation drives the fusion fuel inward, compressing and heating it to the conditions necessary for thermonuclear fusion reactions to self-initiate. Under the proper conditions the thermonuclear reactions will propagate outward in a fusion burn, consuming all of the fuel and liberating more energy than was used to drive the target. This type of ICF target is also called an indirect drive target because the laser beams are not incident directly on the fusion capsule. Indirect drive targets are advantageous because they tend to smooth out imperfections in the laser drive associated with laser energy and uniformity. In the case of NIF a "point design" capsule, shown in Figure 7, sophisticated 3D computer calculations indicate the production about 20 Megajoules of fusion yield in the form of energetic $14 \mathrm{MeV}$ neutrons, $\mathrm{X}$ rays, and gamma rays for about 2 Megajoules of UV light delivered from the 192 laser beams.

Prospects for ignition on NIF continue to improve. ${ }^{35,36}$ Designs supporting indirect-drive, or $\mathrm{x}$-ray drive of ignition capsules in hohraums are becoming more robust as better modeling capability, including full 3-dimensional modeling of capsules and hohlraums allows design trade-off studies to be rapidly performed and design spaces to be optimized. For example, optimization studies have improved plastic capsule performance by a factor of two while allowing ablator roughness to increase by a factor of two, easing fabrication requirements.

New designs using beryllium with graded $\mathrm{Cu}$ dopant are particularly robust, with ablator roughnesses being relaxed by as much as a factor of 10-20 over previous designs and newly optimized polyimide designs. In addition, significant progress has been made in fabricating smooth plastic and beryllium/copper capsules that nearly meet these new design specifications.
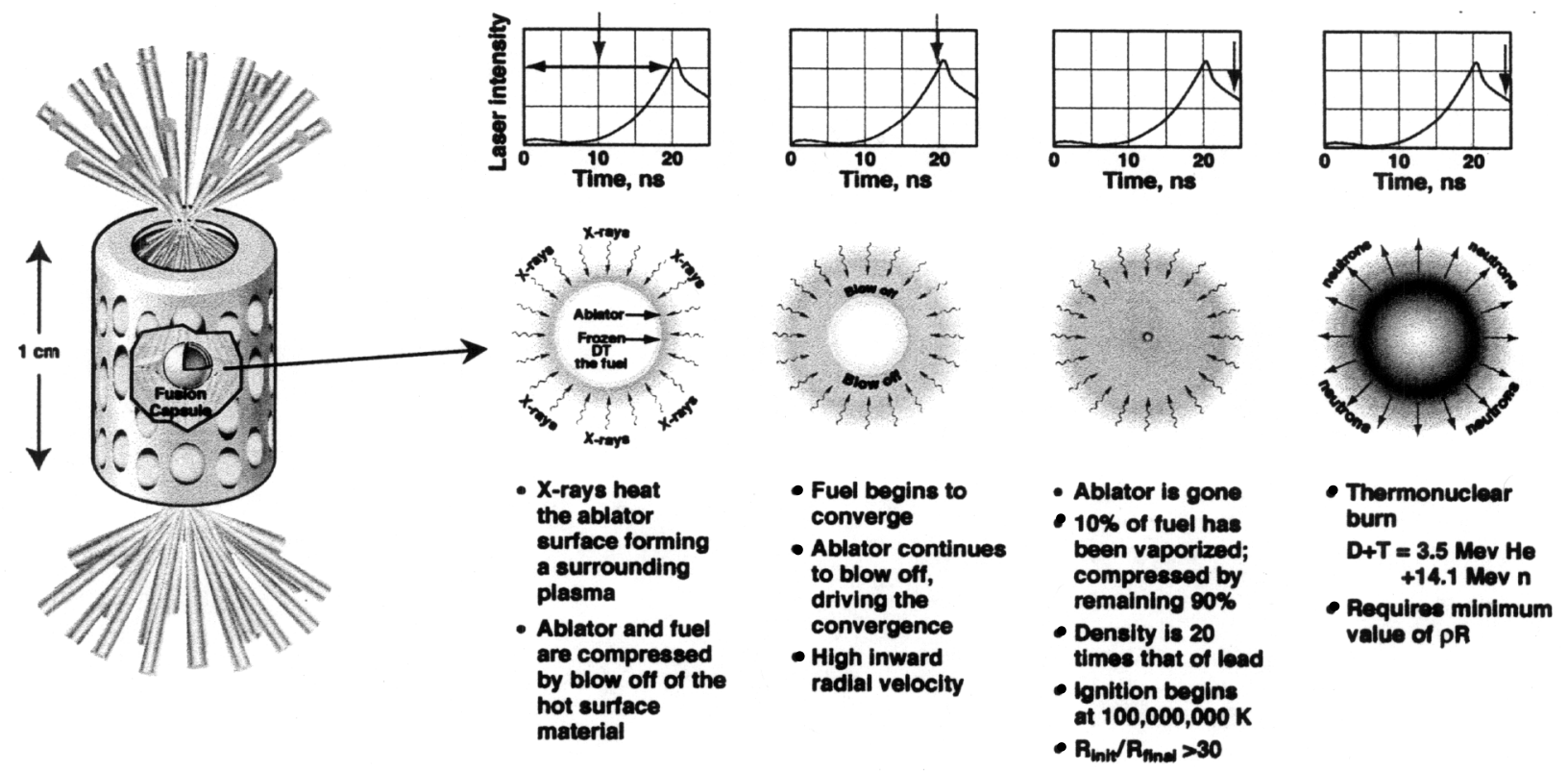

Fig. 6. A schematic representation of a NIF indirect drive hohlraum target is shown on the left. NIF's 192 laser beams are grouped in 48 "quads" of 4 laser beams that are directed in opposite ends of the hohlraum to produce the $x$-ray drive. The time sequence on the right shows how the $\mathrm{x}$-rays interact with the fusion capsule to create ignition and burn with energy gain.

demonstrated. Progress is also being made in developing cryogenic hohlraums with convection mitigation and thermal control. Diffusion filling of a capsule in a hohlraum has also been recently demonstrated and integration of infrared layering, thermal shimming, convection mitigation, and characterization in a $D_{2}$ test system is underway. ${ }^{37}$ 
Hohlraums driven with green or $2 \omega$ laser light from NIF are actively being studied. ${ }^{38}$ Calculations suggest that as much as $1.5 \mathrm{MJ}$ of energy may couple to a capsule at $250 \mathrm{eV}$ drive temperature. However, physical data on $2 \omega$ laser plasma interactions is limited and more work is needed. NIF $2 \omega$ operation has been demonstrated and researchers are studying how to configure some of NIF's early beams for high energy $2 \omega$ LPI studies.

Finally, fast ignition experiments at the University of Osaka, Institute for Laser Engineering, and at Rutherford Laboratory in the UK are providing tantalizing glimpses of possible low energy symmetric heating combined with high power asymmetric drive to induce hot spot ignition conditions in cone-focused targets. ${ }^{39,40}$

A "proof-of-principle" fast ignition experiment at NIF is in the design phase. Laser physicists have determined how NIF's current injection laser, main amplifier, and beam transport system could be modified to allow up to 20 high energy petawatt-class (HEPW) beams to be directed to target chamber center. Initial experiments are being designed to utilize a single kilojoule-class HEPW beam line with 1-30 picosecond pulse width to drive electron or proton cone-focused ignition. This short pulse beam coule be coupled with $250 \mathrm{KJ}$ of NIF's long pulse beams for initial experiments. Initial short pulse capability on NIF could be in place in the 2006 time frame. ${ }^{41}$ Additional HEPW beams in a quad could be installed to provide multi-kilojoule capability.

\section{EXPANDING SCIENTIFIC HORIZONS ON NIF}

The National Academy of Sciences in the United States has recently recognized the exciting scientific frontiers becoming available at the next generation of high-energy-density experimental facilities. ${ }^{42,43}$ Laboratory-based astrophysics experiments, simulating extreme physics phenomena heretofore inaccessible, are now becoming feasible for the first time.

For example, supernovae explosion mechanisms remain uncertain. Recent planar and spherical RT experiments on Nova and Omega showed that instabilities produced in these systems can be quantitatively studied. Figure 7 shows comparison of experiments and simulations showing qualitative similarities in their behavior. In fact a variety of scaled experiments using NIF are possible, studying not only large scale mixing phenomena associated with supernovae, but also radiatively driven shocks that can lead to $2 \mathrm{D}$ jets and $3 \mathrm{D}$ spherical shocks observed in astrophysics as shown in Figure 8. Researchers are assessing NIF's potential for simulating exotic astrophysical systems such as the extended RT systems in the Eagle nebula, immense astrophysical radiative magnetohydrodynamic jets, ${ }^{44}$ and even possibly the incredible physical conditions

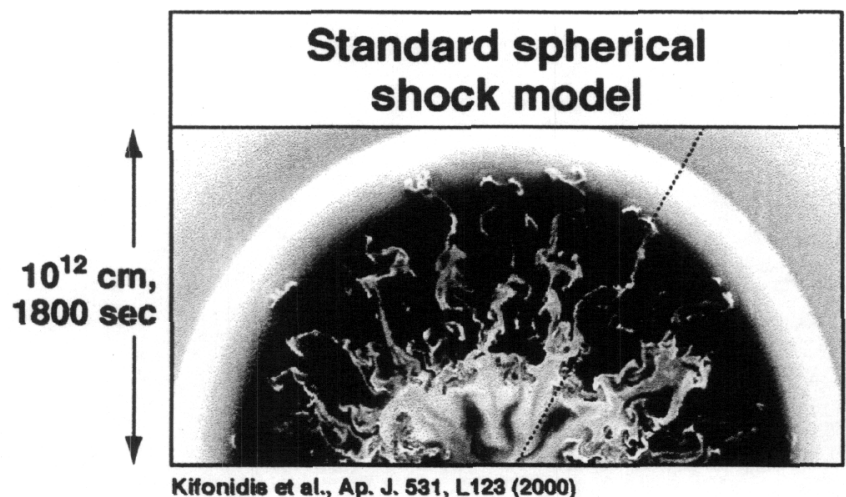

Kifonidis et al., Ap. J. 531, L123 (2000)

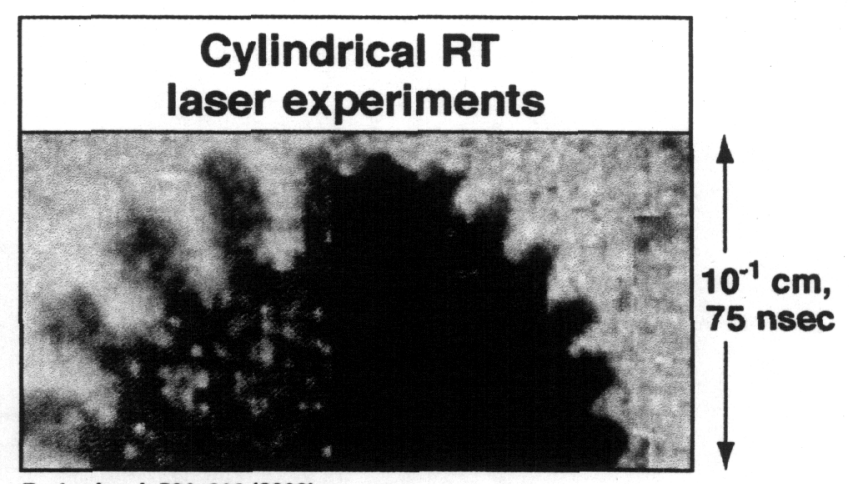

Drake Ap. J. 564, $896(2002)$

Fig. 7. Comparison of instabilities generated in a spherical shock model of supernovae, left, with RT experiments conducted using scaled targets driving by lasers. The image on the right show RT growth between 55 and $75 \mathrm{nsec}$ on a scale of about $0.1 \mathrm{~cm}$, that are qualitatively similar to the supernova model.

that exist only near the surface of a neutron star. ${ }^{45}$ Figure 9 shows examples of these phenomena and associated laser driven analog experiments. Note the extreme scaling in both time and space between laser experiments and the astrophysical objects in these figures. NIF will provide the capability to study larger volume targets for longer times and high fluence, high energy time-resolved $\mathrm{x}$-ray data will help to validate hydrodynamic models that can be scaled to stellar dimensions and times. 


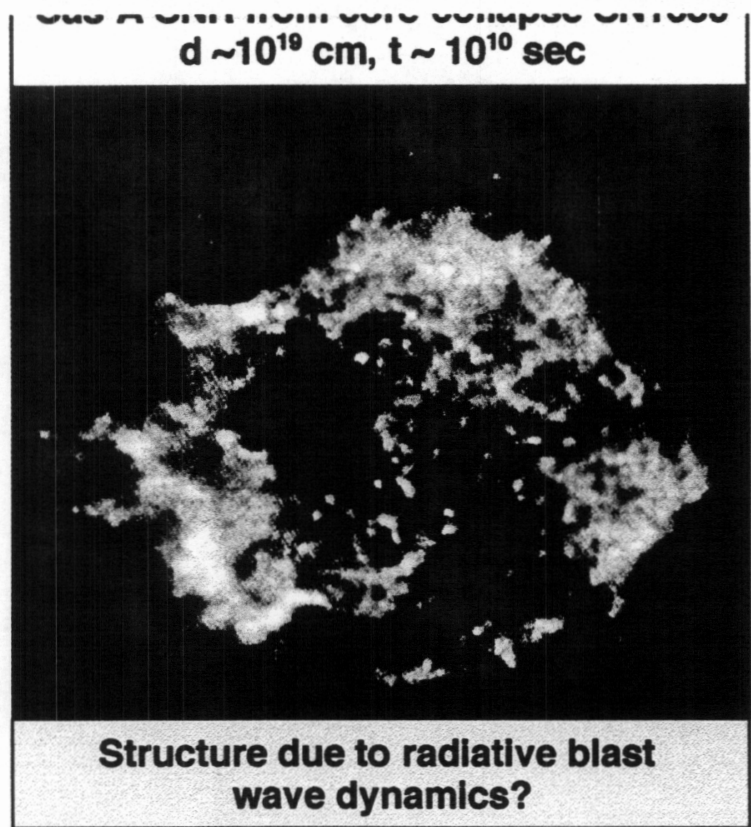

J. P. Huges, Ap. J. 529, L109 (2000)

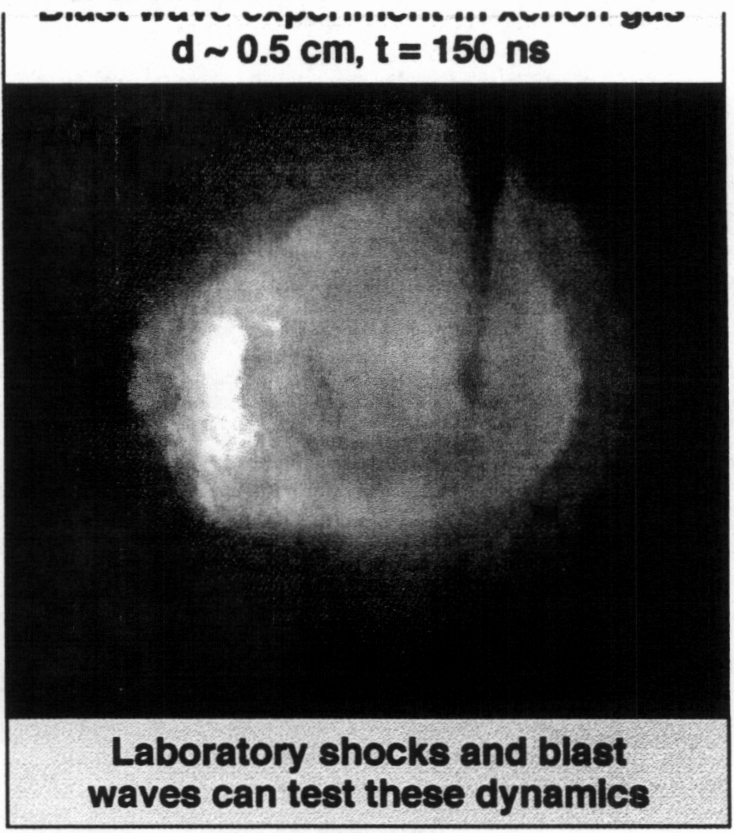

J. F. Hansen et al., submitted to PRL (2003)

Fig. 8. Radiative shocks such as supernova blast waves can be simulated using scaled gas-filled targets illuminated by energetic laser beams. The photograph on the left is a Supernova Remnant (SNR) in Cassiopeia-A, which occurred in the year 1680. In the image on the right a beam incident from the left has initiated an expanding radiatively driven shock that is outrunning the material expansion from the target itself. This is seen as the faint glow surrounding the brighter inner sphere.
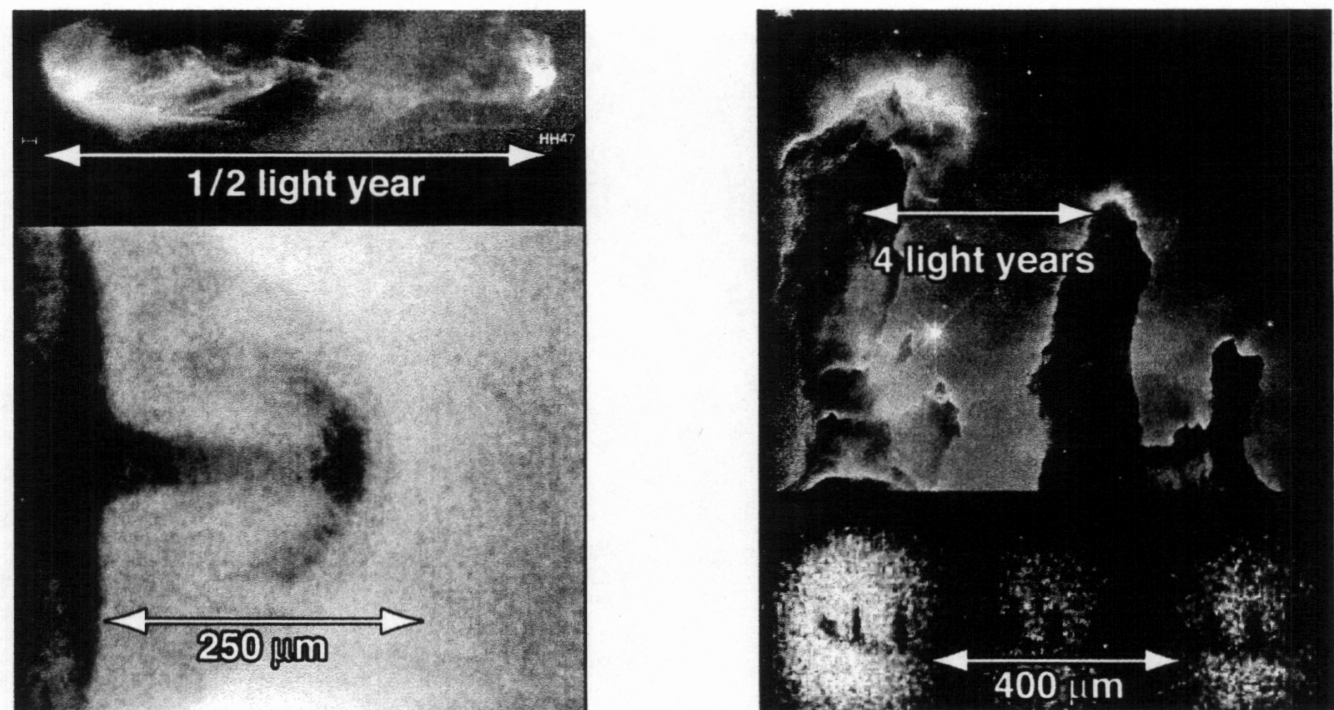

Fig. 9. Additional examples of scaled astrophysical phenomena that can be simulated using lasers. On the left is an astrophysical jet compared with a laser-generated jet using the Omega laser. On the right the striking structures in the Eagle nebula are compared with similar RT structures generated using the Nova laser. 


\section{THE PATH FORWARD TO FULL NIF}

Completion of all 192 laser beams is scheduled for September 2008. We have developed a plan for beam deployment that supports experiments with steadily increasing capability shown in Figure 10. Currently NIF is configured with 4 beams and we are preparing for build out the rest of the laser system beginning in FY 2005. The increasing symmetry and energy available as the number of beams increases enables a variety of target configurations including planar targets, horizontal and vertical half-hohlraums (halfraums), and vertical hohlraums with 4- and 8-fold symmetry that provides approximately 300 shots per year through 2008 for high-energy-density physics, inertial confinement fusion, and basic science. (IS THIS STILL TRUE WITH THE NEW CLUSTER BASED DEPLOYMKENT SCHEME. MAY NEED TO BE RE_WRITTEN). After project completion, NIF is expected to provide approximately 700 shots per year for a wide variety of experimental users as a national user facility. A recent shot campaign on NIF provided three target shots per day over a three-day period, demonstrating the ability to meet the planned 700 shots per year when NIF is fully operational. We have also developed a plan for fielding facility diagnostics that is synchronized to the increasing capability NIF provides.

In addition to diagnostics, the NIF Program includes support for building and commissioning facility capabilities in diffractive optics (phase plates), cryogenic target systems, and target area operations. We are developing a non-ignition cryogenic target capability to be fielded around the time of first cluster. This will be followed with a full cryogenic target system for supporting the campaign of ignition experiments beginning the FY08 time frame.

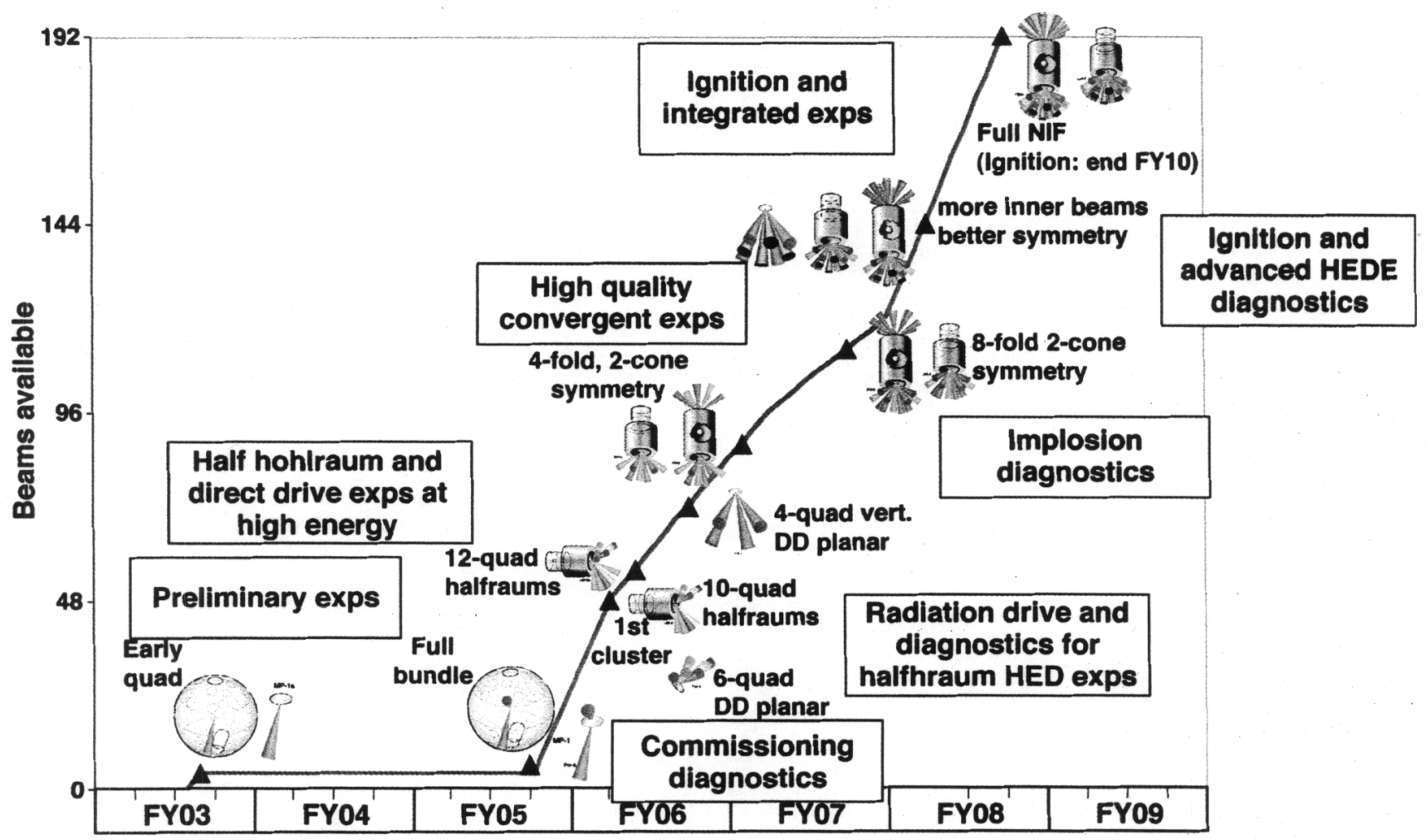

Fig. 10. As additional NIF laser beams are installed, increasing capability becomes available and experimenters can take advantage of beam symmetry and energy to perform increasingly sophisticated experiments. In addition, specialized diagnostics will become available in parallel with the build-out and commissioning of the laser system. 


\section{NIF AS AN INTERNATIONAL SCIENCE CENTER}

The first physics experiments are already being performed on NIF. ${ }^{25}$ Initial experiments are studying laser-plasma interactions, which are important for understanding the propagation of laser beams and the delivery of energy into ignition hohlraums. Figure 11 shows results from a recent experiment directing NIF's first four beams with $16 \mathrm{~kJ}$ of ultraviolet light into a gas-filled target. The $\mathrm{x}$-ray images compare favorably with sophisticated calculations. In the coming year we are planning experiments to study materials equation of state and hydrodynamics of shocked materials.

This unique facility is already be providing the first glimpses of conditions heretofore only found in the most extreme environments under repeatable and well-characterized laboratory conditions for the benefit of a wide variety of scientific users. To assist in the transition from a construction and technology project to a scientific user facility we have been working with the key user communities of NIF, academia, and NNSA to ensure that NIF is fully utilized to produce the highest quality physics data possible.

NNSA has created the position of NIF Director and charged him with developing the governance of user programs. This governance includes high-level NIF advisory committees, an Experimental Planning Advisory Committee (EPAC) with representation from all the user communities, and lower level scheduling committees. The NIF EPAC has begun meeting to familiarize itself with NIF's early capabilities in preparation for wider calls for proposals, the first of which is expected to be in FY05.

Current programmatic guidance for NIF shot allocations provide for approximately $40 \%$ each for HED and ICF, $15 \%$ for basic science and military applications, and $5 \%$ for Director reserved contingency.

As NIF matures we fully expect the facility to evolve to include exciting new capabilities, some of which are mentioned briefly here. The NIF laser system and support buildings have been designed with maximum flexibility for future enhancements such as multi-wavelength operation and high-energy short pulse operation. NIF is ready to deliver the next generation of HED and ICF experimental capability for the US and international scientific communities. ${ }^{45}$
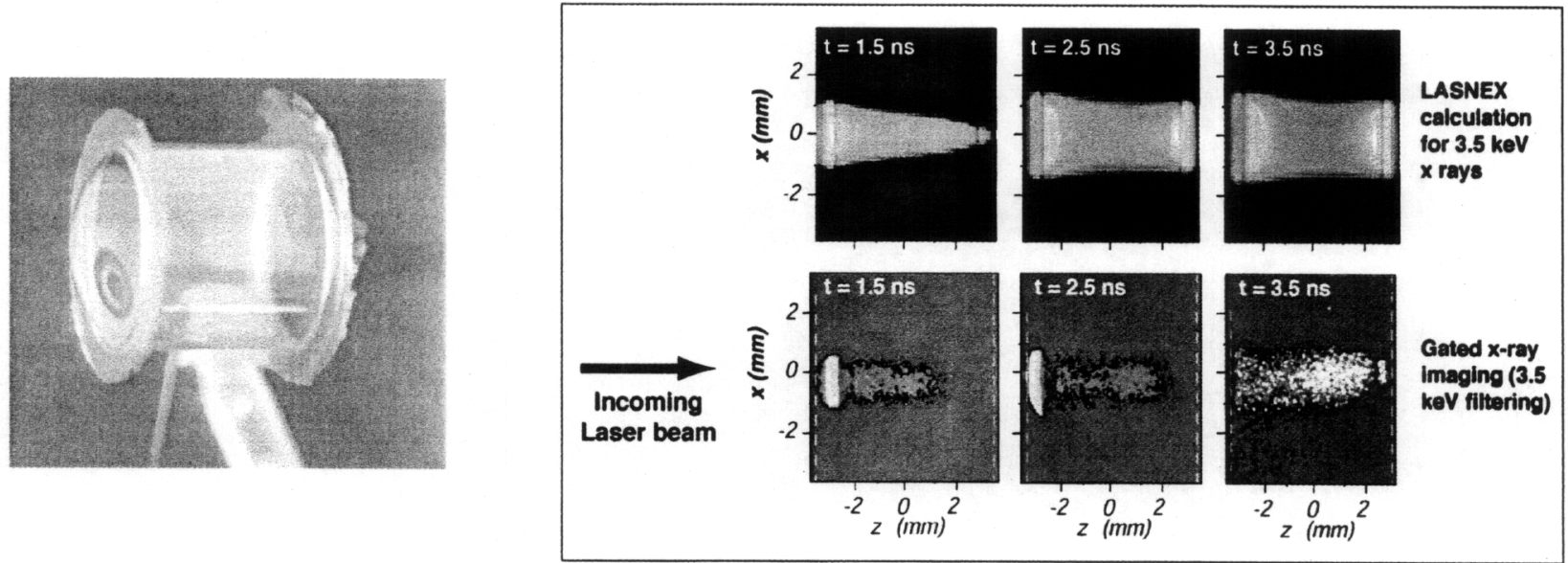

Fig. 11. Laser-plasma interaction experiments have been fielded on NIF using cm-scale $\mathrm{CO}_{2}$ gas-filled targets, shown on the left. Results from the first physics experiments on NIF using these targets are shown on the right using a gated $\mathrm{x}$-ray imaging diagnostic. This data can be compared with computer models that qualitatively agree with the data. 


\section{ACKNOWLEDGMENTS}

This work was performed under the auspices of the U.S. Department of Energy by the University of California, Lawrence Livermore National Laboratory under contract W-7405-Eng-48.

\section{REFERENCES}

1. J. Lindl, Inertial Confinement Fusion: The Quest for Ignition and Energy Gain Using Indirect Drive, Springer-Verlag (1998).

2. Laboratory Microfusion Capability Phase-II Study, prepared by Interscience, Inc. for the Inertial Fusion Division Office of Research and Advanced Technology, ISI-TM9005281, May 31, 1990.

3. Solid State Lasers for Application to Inertial Confinement Fusion (ICF), W. F. Krupke, ed., Proc. SPIE 2633 (1995).

4. C. B. Tarter, Inertial Fusion and Higher Energy Density Science in the United States, Proc. 2001 Conf. On Inertial Fusion Science and Applications (IFSA 2001), K. A. Tanaka, D. D. Meyerhofer, J. Meyer-ter-Vehn, eds., Elsevier, Paris (2002).

5. E. Moses, et al., The National Ignition Facility: Status and Plans for Laser Fusion and High-Energy-Density Experimental Studies, Fusion Science and Technology, 43, 420, (2003).

6. E. Moses, et al., The National lgnition Facility: The World's Largest Optics and Laser System, UCRL-151593-JC, submitted for publication in the SPIE Proc. Of Photonics West, January (2003).

7. E. I. Moses, "National Ignition Fac ility: the world's largest optics and laser system," presented at LASE 2004, Photonics West, San Jose, CA January 2004.

8. M. L. Spaeth, "National Ignition Facility requirements and optical architecture," presented at LASE 2004, Photonics West, San Jose, CA January 2004.

9. R. H. Sawicki, "National Ignition Facility: laser system, beam line design, and construction," presented at LASE 2004, Photonics West, San Jose, CA January 2004.

10. B. M. Van Wonterghem, "National Ignition Facility commissioning and performance," presented at LASE 2004, Photonics West, San Jose, CA January 2004.

11. W. H. Williams, "Optical propagation modeling, W. H. Williams," presented at LASE 2004, Photonics West, San Jose, CA January 2004.

12. M. J. Shaw, C. A, Haynam, "National Ignition Facility laser performance operations model (LPOM," presented at LASE 2004, Photonics West, San Jose, CA January 2004.

13. J. H. Campbell et al., "NIF advanced optical fabrication technology," presented at LASE 2004, Photonics West, San Jose, CA January 2004.

14. T. I. Suratwala et al., "Neodymium glass," presented at LASE 2004, Photonics West, San Jose, CA January 2004.

15. C. J. Stolz et al., "National Ignition Facility transport optics," presented at LASE 2004, Photonics West, San Jose, CA January 2004.

16. R. A. Hawley-Fedder, "NIF pockels cell and frequency conversion crystals," presented at LASE 2004, Photonics West, San Jose, CA January 2004.

17. D. W. Larson, "NIF laser hardware: the line replaceable units," presented at LASE 2004, Photonics West, San Jose, CA January 2004.

18. R. E. Bonanno, "Assembling and installing LRUs for NIF," presented at LASE 2004, Photonics West, San Jose, CA January 2004.

19. J. Wisoff et al., "Architecture and performance of the National Ignition Facility injection laser system," presented at LASE 2004, Photonics West, San Jose, CA January 2004.

20. C. D. Marshall, "NIF main laser system commissioning and performance," presented at LASE 2004, Photonics West, San Jose, CA January 2004.

21. P. A. Arnold et al., "Deployment, commissioning, and operation of plasma electrode pockels cells in the National Ignition Facility," presented at LASE 2004, Photonics West, San Jose, CA January 2004.

22. R. A. Zacharias et al., "National Ignition Facility alignment and wavefront control," presented at LASE 2004, Photonics West, San Jose, CA January 2004.

23. P. J. Wegner, "Final optics system: frequency conversion and beam conditioning," presented at LASE 2004, Photonics West, San Jose, CA January 2004.

24. C. P. J. Barty, "High-energy petawatt lasers and NIF: motivations and challenges," presented at LASE 2004, Photonics West, San Jose, CA January 2004.

25. S. GLENZER, et al., Progress in Long Scale Length Laser-Plasma Interactions, submitted to the Proceedings of the Third International Conference on Inertial Fusion Sciences and Applications, Monterey, September 2003.

26. Figure adapted from Figure 1.1 in "Frontiers in High-Energy-Density Physics: The X-games of Contemporary Science," National Research Council 2003.

27. B. Remington, et al., Materials Science at the Extremes of Pressure and Strain Rate, submitted to the Proceedings of the Third International Conference on Inertial Fusion Sciences and Applications, Monterey, September 2003. 
28. J. Edwards et al., submitted to Phys. Rev. Lett. (2003).

29. B. Remington et al., Met. Mat. Trans. A, in press (2003).

30. T. Boehly, et al., Deuterium Equation of Stae Measurements Using Laser-Driven Shocks, submitted to the Proceedings of the Third International Conference on Inertial Fusion Sciences and Applications, Monterey, September 2003.

31. H.-S. Park et al., SPIE Proceedings on Laser-Generated and Other Laboratory X-Ray and EUV Sources, Optics, and Applications in press (2003).

32. M.D. Perry et al., Rev. Sci. Instr. 70, 265 (1999).

33. P. Celliers et al., NIF as a Platform for High Pressure Shock Wave Equation of State Research, submitted to the Proceedings of the Third International Conference on Inertial Fusion Sciences and Applications, Monterey, September 2003.

34. J. Lorenz, publication in preparation for Journal of Applied Physics, (2003).

35. S. Haan et al., Update On Target Design for the National Ignition Facility, Proc. 2001 Conf. On Inertial Fusion Science and Applications (IFSA 2001), K. A. Tanaka, D. D. Meyerhofer, J. Meyer-ter-Vehn, eds., Elsevier, Paris (2002).

36. M. Herrmann et al., Exploration of the Parameter Space for NIF Ignition Capsules, submitted to the Proceedings of the Third International Conference on Inertial Fusion Sciences and Applications, Monterey, September 2003.

37. T. Bernat Target Technologies for X-ray Drivne Ignition on the NIF, submitted to the Proceedings of the Third International Conference on Inertial Fusion Sciences and Applications, Monterey, September 2003.

38. L. Suter, Prospects for High-gain, High-yield NIF Targets Driven by $2 \omega$ light, submitted to the Proceedings of the Third International Conference on Inertial Fusion Sciences and Applications, Monterey, September 2003.

39. R. Kodama, et al., Fast Heating With a Petawatt Laser as a Step to Ignition, submitted to the Proceedings of the Third International Conference on Inertial Fusion Sciences and Applications, Monterey, September 2003.

40. P. Norreys, et al., Advanced Fast Ignition Studies at the Rutherford Appleton Laboratory, submitted to the Proceedings of the Third International Conference on Inertial Fusion Sciences and Applications, Monterey, September 2003.

41. C. P. J. Barty, et al., Technical Challenges and Motivations for High Energy Petawatt Lasers on NIF, submitted to the Proceedings of the Third International Conference on Inertial Fusion Sciences and Applications, Monterey, September 2003.

42. Connecting Quarks with the Cosmos: Eleven Science Questions for the New Century, National Research Council 2003.

43. Frontiers in High Energy Density Physics: The X-Games of Contemporary Science, National Research Council 2003.

44. B. Remington, High Energy Density Astrophysics in the Laboratory, Proc. 2001 Conf. On Inertial Fusion Science and Applications (IFSA 2001), K. A. Tanaka, D. D. Meyerhofer, J. Meyer-ter-Vehn, eds., Elsevier, Paris (2002).

45. R. Klein et al., Ap. J. 457, L85 (1996).

46. For more information on the National Ignition Facility please visit the NIF web site at http://www.llnl.gov/nif 